\title{
Special Issue Featuring Papers from the 10th Asian Thermal Spray Conference 2020
}

(c) ASM International 2021

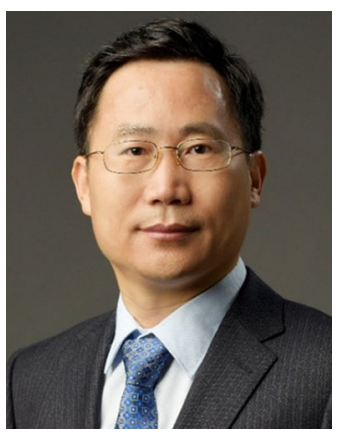

Hua Li

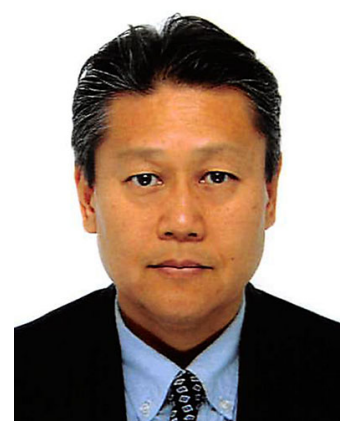

Kazuhiro Ogawa

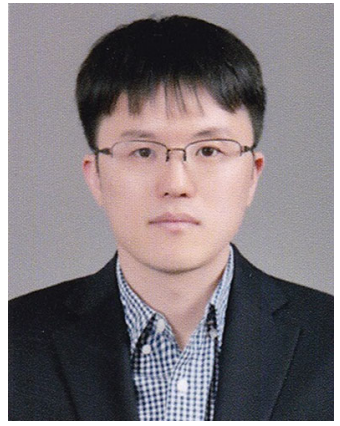

Hunkwan Park

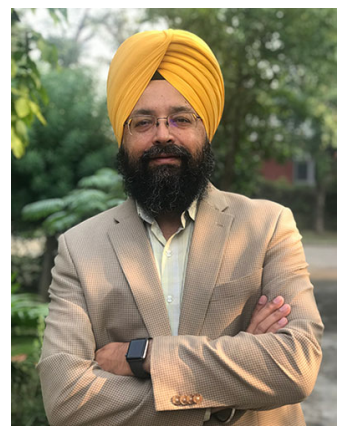

Harpreet Singh

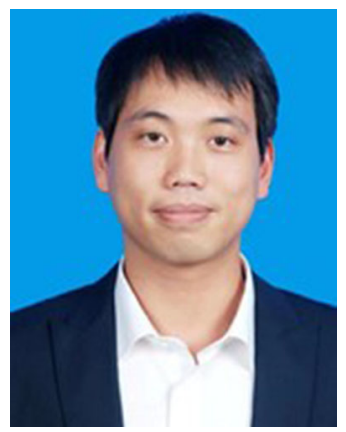

Xiuyong Chen
This special issue of the Journal of Thermal Spray Technology presents a selection of articles that were presented at the 10th Asian Thermal Spray Conference 2020 (the 10th ATSC 2020) and expanded into full-length, peer-reviewed articles. The conference was held in Ningbo, China, on November 1-3, 2020, and was organized by the Asian Thermal Spray Society and hosted by Ningbo Institute of
Materials Technology and Engineering, Chinese Academy of Sciences.

The global worth of the market of thermal spray coatings was over $\$ 8$ billion in 2016 and $\$ 10.6$ billion in 2019 and is expected to grow to $\$ 14.6$ billion in 2024 at a compound annual growth rate (CAGR) of 6.7\% from 2019 to 2024 [Kunal Ahuja, Amit Rawat, Thermal Spray 
Coating Market, Global Market Insights, 2018]. The share of Asia Pacific countries in the thermal spray market was valued at $21.5 \%$ of revenues in the global thermal spray coatings market. It is projected to expand at an accelerated CAGR during the forecast period, with China, Japan, and India dominating the market [Asia-Pacific Thermal Spray Market-Growth, Trends, Covid-19 Impact, and Forecasts (2021-2026), Mordor Intelligence, 2019]. The market growth is attributed to the increasing utilization of thermal spray coatings in aerospace, automotive, energy and power, and other end-user industries [Global Thermal Spray Coatings Market Size 2017 By Product (Metals, Ceramics, Intermetallic, Polymers, and Others), by Application (Aerospace, Industrial Gas Turbine, Automotive, and Others), by Region and Forecast 2018 to 2025, Thermal Spray Coatings Market, 2017]. In Asian countries, new coating materials, thermal spray processes, and applications have emerged from traditional remanufacturing to advanced surface functionalization.

During the past 15 years, as an invaluable information, dissemination, and exchange platform among Asian thermal spray communities, ATSC has become one of the largest, most influential, and professional thermal spray events in Asia. ATSC is the flagship event of the Asian Thermal Spray Society; it is held twice every 3 years in Asian countries with the first ATSC being held in Nagoya, Japan in 2005. The topics of this ATSC covered original advances in thermal spray processes, structural and functional coatings, and testing methods for coatings. The conference featured sessions on most recently developed coating materials, cold spray and solution/suspension-based spray processes, hybrid spray processes, process control and diagnostics, modeling and simulation, functional and structural properties of thermal sprayed coatings, and new market opportunities.

Regardless of the long-lasting impact of the COVID-19 pandemic, over 350 from both academia and industry attended the conference in person and more than 100 worldwide participants connected virtually to the conference. They joined for keynote lectures, invited oral presentations, posters, and academic discussions during the conference.

The presentations that were delivered at ATSC shared the innovative and applied nature of the research and technology development activities in the thermal spray field. The articles in this special issue were selected from 90 articles that were included in the Proceedings of the ATSC 2020, with 46 articles invited for expansion and submission for peer review in the Journal of Thermal Spray Technology. They will serve as valuable references for researchers and engineers to understand and develop thermal spray techniques for new coatings and novel coating properties to meet current and future industry needs.

We would like to thank all the reviewers for their timely and expert reviews for the invited articles and the authors for their fine contributions and their thoughtful responses to the comments of the reviewers.

\section{Lead Guest Editor}

\section{Hua Li}

Ningbo Institute of Materials Technology and

Engineering

Chinese Academy of Sciences

Ningbo, China

Contact e-mail: lihua@nimte.ac.cn

\section{Guest Editors}

\section{Kazuhiro Ogawa}

Tohoku University

Sendai, Miyagi, Japan

Hunkwan Park

Korea Institute of Materials Science

Changwon-si, Gyeongsangnam-do, Korea

\section{Harpreet Singh}

Indian Institute of Technology Ropar

Rupnagar, Punjab, India

\section{Xiuyong Chen}

Ningbo Institute of Materials Technology and

Engineering

Chinese Academy of Sciences

Ningbo, China

Publisher's Note Springer Nature remains neutral with regard to jurisdictional claims in published maps and institutional affiliations. 